\title{
Role of Pharmacy Education in National Development of Bangladesh: A Scope for Public and Private Sectors
}

\author{
Gazi Mahabubul Alam ${ }^{\mathrm{a}}$ and Abul Quasem Al-Amin ${ }^{\mathrm{b}^{*}}$ \\ aUnit for the Academic Performance Enhancement, Office of the Vice Chancellor, University of Malaya, Malaysia \\ 'International Business School (IBS), University Teknologi Malaysia (UTM), Jalan Semarak 54100 Kuala Lumpur, Malaysia
}

\begin{abstract}
Objectives: To explore the avenues in order provide a better strategic action plan that may help the Pharmacy Education to contribute for both public and private benefits. Methods: This paper adopts a qualitative research design and uses Bangladesh as a case. Qualitative methods were used that allowed interviewees to express their views in a free and personal way, giving as much prominence as possible to their thematic associations. Analysis of secondary data and intellectual debates were used with an aim of generating a discourse. Results/ Findings: The key finding shows that within the current climate; while pharmacy education provided by the public counterpart contributes producing highly skilled group who are either engaged with international market or internationally linked local companies, the private sector meets the demand of 'diploma diseases'. Consequently, the development of community pharmacists is ignored. Within this verdict, graduates from different fields are fulfilling the market which does not allow this sector to be institutionalized for contributing largely. Conclusion: The paper argues that Pharmacy Education can be able to contribute for both public and private benefits if a realistic pattern is ensured on its operation.
\end{abstract}

Keywords: Pharmacy Education, Private and Public Sectors, Professional Education, Legislation, Bangladesh.

\section{INTRODUCTION}

Operation and delivery of Pharmacy Education globally started in the provision of higher education with the support received from the respective governance and regulatory controlling agencies and professional bodies in order to ensure proper quality control mechanism. ${ }^{1}$ Later, for ensuring both economic and social developments, developed countries started providing Pharmacy Education by inventing various types of programmes and courses which include different types of diploma (higher secondary) to research studies. ${ }^{2}$ This helped the developed nations in producing semiskilled, skilled and highly-skilled professionals who can serve in different required cycles involved in Pharmaceutical Industry which are comprised of companies that make, patent and sell drugs. ${ }^{3}$

The operation of Pharmacy Education in developing countries is still limited to the provision of higher education that produced theoretically 'skilled' professionals by providing degrees. ${ }^{4}$ It is thus the demand of 'highly-skilled' and 'semi-skilled' professionals remains unattended. In absence of these essential two groups for the total development of the industry, Pharmaceutical Industry in developing nations suffers various constraints for its high fostering. ${ }^{5}$ This sometime demotivates the 'skilled group'. Consequently, skilled graduates leave for overseas where they find more prosperous jobs. For the budgetary constraints, developing countries are not able to offer Pharmacy Education delivering
Submission Date : 26-05-14 Revision Date : 18-08-14 Accepted Date : 03-09-14

DOI: $10.5530 / \mathrm{ijper} .48 .4 .3$

Address for correspondence:

Prof. Gazi Mahabubul Alam

Professor of Education Economics, Planning and Management Unit for the Academic Performance Enhancement, Office of the Vice Chancellor, University of Malaya, Malaysia

Phone: +603 21805045

E-mail: abulquasem@ibs. utm.my

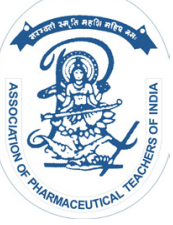

www.ijper.org 
various courses to different targeted groups that provide complete cycle of professionals required. ${ }^{6}$ On the other hand, due to poor economic backdrop and lack of full pledged industries, skilled professionals also migrate to suitable destinations away from their home countries. This situation in developing nations questions on the primary contribution of Pharmacy Education on national development. ${ }^{7}$ While critics blame the stake holders involved in the sector of Pharmacy Education for these shortfalls, adherents argue that Pharmacy Education does not live in isolation; it is therefore the overall national and regional short comings and constraints in developing countries which are responsible. ${ }^{8}$

Lately, private education has started working in developing nations with a heavy engagement at the diploma and undergraduate levels. ${ }^{9}$ Some of the countries are putting efforts to use private education effectivelyidentifying a new purposeful role that it can play by placing a decent governance and regulatory mechanism.

Bangladesh is a developing nation which is not an exception in experiencing the situations that other developing nations do. However, only two pieces of earlier studies available. $^{7-8}$ these are testify that while Pharmacy Education in Bangladesh contributes reasonably for economic development, contribution for social development is insignificant.

This article examines the role that is currently played by Pharmacy Education. It also identifies the gaps which can be improved through a revised action plan for both public and private counterparts. The article also provides a direction for policy makers for further development. The main aim of this paper is to explore the avenues that help the Pharmacy Education to contribute for both public and private benefits. In order to achieve this aims, a number of suggestions and strategic guidelines based on findings are provided before the conclusion is made. This paper sees that a great attention needs to be paid to develop community pharmacists in order to have a sustainable pharmaceutical sector that can contribute for both public and private benefits. Moreover, this paper also argues that a balanced salary structure is needed within the sector to address existing huge disparities.

\section{CONCEPTION ON NATIONAL DEVELOPMENT}

National development is a key agenda for many countries, especially for the under developed and developing countries. According to Alam. ${ }^{9}$ Alam $^{10}$ et al. Alam ${ }^{11-12}$ et al. Alam, ${ }^{13}$ et al. Alam Kazi1. ${ }^{14}$ the core business of education is to work as the key agent of national development, either as a way of developing human capac- ity, increasing the skilled work force for modernization or as a matter of personal freedom, development of capacity and empowerment.

\section{NATIONAL DEVELOPMENT FROM VARIOUS PERSPECTIVES}

According to Thomas and Potter ${ }^{15}$, "all definitions of development contain the central notion of a process of change from a less desirable to a more desirable kind of society... development of what? How and what is "desirable" defined, and by whom? How the progression can be achieved?" Hence, the primary concern for national development is about the development of "what".

From the literature, it appears that the intention and under pinning concept of national development evolve over time. According to Alam et $\mathrm{al}^{16}$, since 1950 s there have been at least three main schools of thought on the concept of national development. They are: (a) economist's perspective, (b) sociologist's perspective and (c) human needs theorists' perspective.

Primarily, the economists (e.g. Bernstein, Shultz, Psacharapolous) view development in terms of the nation's relative prosperity, which is measured by the Gross National Product (GNP), as highlighted by Alam et al. ${ }^{16}$ However, there is a concern that greater income does not guarantee greater buying power, more choices or better quality of life. This is partly due to globalization and free economic trade that made it challenging to maintain a reasonable inflation rate. An interesting point is noted by Alam ${ }^{11-12}$ states that if there is an exceptionally high gap existing amongst GNI (Gross National Income) GNP and GDP (Gross National Product, and Gross Domestic Income), national develop will not sustain or would halt the development ultimately for two reasons:

- If the GNI is enormously lower than GNP and GDP, people of the producing nations cannot survive since a higher cost has already been paid off for the GPD and GNP.

- If the GNI is extremely higher than GDP and GNP, the competitive nation will hunt the advantages supplying the desired products to the international community once they find out the clue. This is easier to find out as the recent explosion of IT and ICT become available to all.

A further point was raised as a number of nations increase their GDP, GNP and GNI with the help of importing raw materials and other inevitable supports needed in the $21^{\text {st }}$ century (i.e. Internet, global transit and protocol) from one specific region or nation, it would not help them as it will provide compound escalating benefits to that specific region or nation. Therefore on 
balance, those countries will face gruelling challenges on bilateral and multilateral business competition due to shortage and low value of foreign currency. This situation would be graver with more globalisation and internationalization.

More importantly, growth in economy without development in politics and society may lead to corruption caused by lack of transparency, maturity of the society and participation of the individuals within a nation. ${ }^{11}$ Development in politics includes separation of power among the executive, legislature, and judiciary, and its transparency, with a free and fair election for the government etc. Development in society includes maturity of the society wanting transparency, fairness, security, knowledge, freedom of choice and participation in the decision making for the society. The concerns rose from all these aspects have led to the emergence of another school of thought, i.e. the sociologists' perspective.

According to Alam et al. ${ }^{13}$ sociologists (e.g. McClelland, Weber, Inkeles, Smith) propose that a country's modernization leads to economic development and a modern society, which has similar economies, societies and politics as those in the prosperous West. ${ }^{15}$ The modernization transformation agents are education, technology and industrialization. However, the word "modern" is an abstract and broad concept, and can be interpreted from different perspectives in different contexts. Even the different developed countries from the West interpreted it differently. For example, USA promotes liberty or freedom of choice much more than harmony and unity of the society. Comparatively, Finland is regarded as a more wholesome society, with richness in economies and mature social behaviours. According to the UNDP, ${ }^{17}$ Finland is top ranked in terms of Transparent Country Placing (Transparency International) with high GDP per capita. In short, developing countries, such as Malaysia, need to have a common understanding within the society, regardless of the race, ethnicity, religion and culture, as well as their definition and choice towards modern society. In addition, this consensus needs to be well-supported by the national development and educational strategies. ${ }^{9,11}$ On the other hand, the social contract should not undermine the individuals' need and free will to practise the freedom of speech and choice, which is the core belief of the human needs theorists.

Human needs theorists (e.g. Seers, Sen, Edwards) consider national development from a human needs perspective. According to Alam et al., ${ }^{911}$ the emphasis was not so heavily focused on economic growth as the primary indicator of development, but more on assessing the needs of individuals: their freedom, equity, participation and empowerment to fulfil their potential capabilities. ${ }^{15}$ However, the understanding of freedom, for example, may differ from context to context, especially between the West and East. Some positive freedom from one country's perspective can be viewed negatively in other countries' and even within the same country, given the differences in race, age and religion etc. Therefore, it is important for the developing countries to have a clear understanding of human needs that is rooted in the culture of the countries. It is also vital to recognize that the prospect of an individual is heavily dependent on the economic, social and political development of a country. ${ }^{11}$ For instance, the primary focus of many under developed and developing countries is to increase the Gross National Income and to reduce poverty within the countries so that all the citizens can live a decent life. Some developing countries believe that it is more crucial to maintain the harmony and unity of their respective countries, instead of promoting individual rights and freedom. In those instances, individual freedom and equity may not be the primary concern at that point of time.

In short, the three schools of thought have their own roles to play in national development. However, due to the primary fundamental role of the government in ensuring that its people have access to basic fundamental goods, utilities and services for survival; governments around the world tend to put their primary focus in economic development, before addressing their social and political development as well as the individual human needs. Apart from that, it is also observed that economic development without the complement of social and political development may lead to corruption and eventually, the economics of the country may not be sustainable. ${ }^{11}$ At the same time, modernization of a society relies on the economic wealth of a country too. Hence, economic, social and political developments are highly interdependent. However, it is also important to take note that the ultimate purpose of national development is to improve the quality of life of the individuals' in the country, by enlarging the people's choice. ${ }^{17}$ Thereby, economic, social and political development without addressing the individual human needs cannot be considered as truly achieving a meaningful national development.

\section{RESEARCH DESIGN}

This is a paper which aims at generating a discourse through the analysis of secondary data and intellectual debates. In order of obtain information, a number of related official web sites, scholarly sites hosted by dif- 
ferent organisations and blog sites are browsed. Moreover, data received through a fieldwork of two weeks also supplement. Many of the arguments are also made through the analysis of the data received through fieldwork.

Qualitative methods were used that allowed interviewees to express their views in a free and personal way, giving as much prominence as possible to their thematic associations.

\section{Semi-structured interviews by qualitative approach were held with:}

- Key personnel at the Ministry of Health and Family Planning in Bangladesh

- Personnel involved with Bangladesh Pharmaceutical Society

- Key personnel at Directorate General of Drug Administration and Pharmacy

- Council of Bangladesh (PCB)

- Stakeholders of both private and public education delivering Pharmacy

- Education

- Key personnel involved with Bangladesh Technical Education Board (BTEB)

Empirical survey was also conducted by the questionnaires given to the randomly selected students studying Pharmacy Education and students facing admissions tests to public/private sectors.

The paper will also concentrate on the use of data collected from document review and observation.

\section{FINDINGS AND DISCUSSION}

The writing that follows includes a number of subsections to explain the findings of this study. A scholarly interpretation is also made at the following subsections in order to provide the strategic plan that Bangladesh can adopt for further development.

\section{HISTORY AND DEVELOPMENT OF PHARMACY EDUCATION}

Having no official recognition of pharmacy as a profession in the region, Dhaka University (DU) located in East Pakistan under the regime of Pakistan started offering Pharmacy Education in 1964. ${ }^{18}$ Department of Pharmacy waslately converted into a faculty which offered its first undergraduate programme in 1964. After one year of the graduationof first batch, in 1969, DU started offering Master's programme. ${ }^{18}$ The duration of initially offered undergraduate programme was 3 years which later extended to four years in 1996. In order to have an international validation, the undergraduate programme was further extended to five years. However, without revising the old syllabus and curricula, the extension of one more year failedto achieve a full international accreditation. $^{7}$ It is therefore graduates from universities in Bangladesh are not allowed to sit for pharmacy registration examinationin many countries especially in the USA. ${ }^{7}$ However, things may change in near future as recently more institutional supports have been provided for Pharmacy Education.

In the late 1980s to1990s, three more public universities joined in the boat. ${ }^{18}$ Lately, additionalthree more public universities and twenty two private universities have started working in the area of Pharmacy Education with questionable quality (Table 1).The overall quality of pharmacy education in Bangladesh is debate able comparing to an international standard. Delivering Pharmacy Education by private counter part without ensuring proper infrastructure and moderate course curricula has become a symbol of satisfying the need of 'diploma disease' for the clients. ${ }^{6}$ Both public and private universities offer bachelor and master's programmes.

According to Pharmacy Council Bangladesh(PCB), three public and thirty one private institutions also offer a three-year diploma programmes. According to Alam ${ }^{9}$, Alam et al. ${ }^{10}$, Alam, et al. ${ }^{11-12}$, Alam, et al. ${ }^{13}$, and Alam, Kazi ${ }^{14}$ the target of the university level Pharmacy Education in Bangladesh is to supply the man power needed for pharmaceutical manufacturing industries, the diploma level targets the candidates who intend work for both provisions (manufacturing industry and hospital). While supplying professionals for hospital and clinicis a new phenomenon for Pharmacy Education, the provision of supplying any form of pharmaceutical knowledge to 'medicine-sellers in Pharmacies' is completely ignored. ${ }^{8}$ Neither the state policy nor education system makes them comply to have aminimum standard as chemists and druggist. This develops huge social decadence.

\section{PUBLIC SECTOR FOR TERTIARY LEVEL PHARMACY EDUCATION}

DU started the Pharmacy Education programme with 28 students in 1964. By now the yearly enrolment capacity in DU is 70 (Table 1). The second public university is to offer the programme Jahangirnagar University which started the programme after 26 years of DU. ${ }^{19}$ The success of DU in producing graduates and gradual increase of demand created a huge market but the supply of graduates was very limited by the academia in Bangladesh. It is therefore the jobs were 
Table 1. Public Universities Offering Pharmacy with Location and Intake Capacity Courses

\begin{tabular}{llcccc} 
SI & \multicolumn{1}{c}{ Name of University } & Location & $\begin{array}{c}\text { Year of } \\
\text { Establishment }\end{array}$ & $\begin{array}{c}\text { Enrolment } \\
\text { capacity per } \\
\text { year }\end{array}$ & $\begin{array}{c}\text { Nature of Accreditation } \\
\text { by the PBC }\end{array}$ \\
\hline 1. & University of Dhaka & Dhaka & 1964 & 70 & Permanent \\
2. & University of Jahangir nagar & Savar, Dhaka & 1985 & 55 & Permanent \\
3. $\quad$ University of Rajshahi & Rajshahi & 1990 & 45 & Permanent \\
4. $\quad$ University of Khulna & Khulna & 1997 & 37 & Temporary \\
5. $\quad$ Noakhali Science and Technology & Noakhali & 2006 & 50 & Temporary \\
6. $\quad$ Jagannath University & Dhaka & 2009 & 20 & Temporary \\
7. $\quad$ University of Jessore & Jessore & 2010 & & Temporary \\
\hline
\end{tabular}

Source: Complied data from UGC and $\mathrm{PCB}^{19}$

often taken by the candidates who were absorbed into the jobs by hands-on training or through 'formal or informal apprenticeship'. Until, 2012, total enrolment capacity in seven public universities in each year is 277 (Table 1). Of seven universities, three were established in the late 2000s and their accreditation was on a temporary basis (Table 1). The products delivered by, Dhaka University, Jahangirnagar University and Khulna University earned reputation. Unfortunately, graduates from other universities did not have such a good reputation. ${ }^{7}$ The geographic location of public university is cosmopolitan because they are located in Dhakaor nearby. ${ }^{19}$ With a number of limitations (lack of space, class rooms, laboratory facilities and specialized equipment and more importantly qualified faculty members), public universities are still the number one choice to study Pharmacy Education because the situation are worse in the private counterparts. ${ }^{7}$ Moreover, a high tuition fees in the private sector not only demotivates and but also restricts the poor students to use private sector. $^{6}$

\section{PRIVATE SECTOR FOR TERTIARY LEVEL PHARMACY EDUCATION}

Lack of supply for a long period created a huge demand and a fairly big market. This encouraged private sector to work in this area without having a decent required experience and without being ready to operate such a 'heavy weighted' professional programme. The establishment of private university in Bangladesh was initiated through the Private University Act 1992. Until 2011, 22 private universities (Table 2) of 58 are offering pharmacy courses. The universities offering pharmacy programmewere not homogenously distributed throughout the country (Table 2). For instance, of the
22 universities, 18 are located in the capital city Dhaka and the rest of them are located in Chittagong. There is no private university in Rajshahi, Khulna, Sylhet, Barisal, Rangpur, Maymensingh, and Comilla regions to offer pharmacy courses. Unfortunately, most of the private universities offering pharmacy courses do not have their own campuses.

Unexceptionally, Private Higher Education (PHE) is the second choice for students and their guardians. Usually, the less capable and not-so-bright students from a well-off background only consider studying a popular and job-oriented subject in the PHE after being rejected by public higher education. Data confirm that many students who are not-so-intelligent pursuing pharmacy programmes which are beyond their intellectual capacity ${ }^{6}$ In the highest level, these students may be able to pursue diploma level programme, but in order to earn money, many private universities are giving them a scope to have a prestigious degree. This will definitely provide negative result for Pharmacy Education in the long run.

Moreover, the number of trained and qualified faculty members is also scarce in those universities as per UGC (University Grants Commission) guidelines because academics from public counterparts are mainly shared with the private sector. Although the UGC and PCB have been trying to upgrade the pharmacy education in Bangladesh, there are still a lot to be accomplished.

\section{DIPLOMA IN PHARMACY EDUCATION BY BOTH SECTORS}

The PCB also regulates 3-year diploma of pharmacy courses. Three public Institutes are offering a 3-year 
Table 2. Private Universities Offering Pharmacy Courses with Location.

\begin{tabular}{|c|c|c|c|c|}
\hline SI & Name of University & Location & $\begin{array}{c}\text { Year of } \\
\text { Establishment }\end{array}$ & $\begin{array}{c}\text { Nature of } \\
\text { Accreditation by } \\
\text { the PBC }\end{array}$ \\
\hline 1. & University of Science and Technology & Chittagong & 1994 & $\mathrm{PA}^{*}$ \\
\hline 2. & The University of Asia Pacific & Dhaka & 1996 & PA \\
\hline 3. & Gono Biswabiddyalay & Dhaka & 1998 & PA \\
\hline 4. & Manarat International University & Dhaka & 2003 & PA \\
\hline 5. & State University of Bangladesh & Dhaka & 2003 & PA \\
\hline 6. & East-West University & Dhaka & 2003 & PA \\
\hline 7. & Southeast University & Dhaka & 2003 & PA \\
\hline 8. & Northern University & Dhaka & 2003 & PA \\
\hline 9. & Primeasia University & Dhaka & 2003 & PA \\
\hline 10. & Stamford University Bangladesh & Dhaka & 2003 & PA \\
\hline 11. & University of Development Alternative & Dhaka & 2002 & PA \\
\hline 12. & North South University & Dhaka & 2005 & PA \\
\hline 13. & Dhaka International University & Dhaka & 2006 & PA \\
\hline 14. & Southern University Bangladesh & Chittagong & 2006 & PA \\
\hline 15. & International Islamic University, Chittagong & Chittagong \& Dhaka & 2006 & PA \\
\hline 16. & BGC Trust University of Bangladesh & Chittagong & 2006 & PA \\
\hline 17. & Bangladesh University & Dhaka & ----- & PA \\
\hline 18. & Atish Dipankar University of Science and Technology & Dhaka & ---- & PA \\
\hline 19. & Daffodil International University & Dhaka & ----- & PA \\
\hline 20. & World University of Bangladesh & Dhaka & ---- & PA \\
\hline 21. & Brac University & Dhaka & ----- & --- \\
\hline 22. & ASA University & Dhaka & ----- & --- \\
\hline
\end{tabular}

*PA means provisional accreditation

Source: Complied data from UGC and $\mathrm{PCB}^{19}$

diploma programme in Pharmacy. Of three, two are located in Dhaka and one of them isoperated by 'Armed Forces in Bangladesh' (Table 3). A number of private institutes with a semi-diversified location arealso offering a 3-year diploma in pharmacy (Table 3). Those Secondary School Certificate graduates in science group are eligible to be enrolled into 3-year diploma in pharmacy course. These diploma graduates obtain ' $\mathrm{B}$ ' grade registration directly from PCB.
No additional examination is required for registration because PCB directly regulates the curriculum and examinations of this course. Moreover, PCB also regulates pharmacy certificate course. Those, who have passed SSC in any group can take 3-month special courses designed and jointly conducted by Bangladesh Pharmaceutical Society (BPS) (www.bps-bd. org) and Bangladesh Chemists and Druggists Society (BCDS) and can sit for the examination. Those 
Table 3. Public and Private Institutes Offering Diploma in Pharmacy with Location

a) Public

\begin{tabular}{|c|c|c|c|c|c|}
\hline SI & Name & Location & SI & Name & Location \\
\hline 1. & Institute of Health Technology & Dhaka & 15. & Rumdu Institute of Health Technology & Mymensingh \\
\hline 2. & Institute of Health Technology & Rajshahi & 16. & $\begin{array}{l}\text { Greenview Institute of Health } \\
\text { Technology }\end{array}$ & Dhaka \\
\hline 3. & Armed Forces Medical Institutes & Dhaka & 17. & $\begin{array}{l}\text { Shaheed SA Memorial Medical } \\
\text { Institute }\end{array}$ & Dhaka \\
\hline \multicolumn{3}{|c|}{ b) Private } & 18. & $\begin{array}{l}\text { Institute of Medical and Dental } \\
\text { Technology }\end{array}$ & Tangail \\
\hline 1. & $\begin{array}{l}\text { Bangladesh Institute of Medical and } \\
\text { Dental Technology }\end{array}$ & Dhaka & 19. & $\begin{array}{l}\text { Fortune Institute of Health } \\
\text { Technology }\end{array}$ & Dhaka \\
\hline 2. & $\begin{array}{l}\text { National Institute of Medical and Dental } \\
\text { Technology }\end{array}$ & Dhaka & 20. & $\begin{array}{l}\text { New lab Institute of Medical } \\
\text { Technology }\end{array}$ & Dhaka \\
\hline 3. & International Institute of Health Science & Dhaka & 21. & $\begin{array}{l}\text { Rajshahi Institute of Medical } \\
\text { Technology }\end{array}$ & Rajshahi \\
\hline 4. & Psyche Institute of Medical Technology & Dhaka & 22. & Prime Institute of Medical Technology & Rajshahi \\
\hline 5. & Marks Institute of Medical Technology & Dhaka & 23. & Dhaka Institute of Health Technology & Dhaka \\
\hline 6. & National Institute of Medical Technology & Dhaka & 24. & $\begin{array}{l}\text { Prince Institute of Medical } \\
\text { Technology }\end{array}$ & Dhaka \\
\hline 7. & Institute of Medical Technology & Dhaka & 25. & $\begin{array}{l}\text { Islami Bank Institute of Health } \\
\text { Technology }\end{array}$ & Rajshahi \\
\hline 8. & $\begin{array}{l}\text { Chittagong Institute of Medical } \\
\text { Technology }\end{array}$ & Chittagong & 26. & Psyche Institute of Health Technology & Bogra \\
\hline 9. & $\begin{array}{l}\text { Healthways Institute of Medical } \\
\text { Technology }\end{array}$ & Bogra & 27. & $\begin{array}{l}\text { Institute of British Colombia Medical } \\
\text { Technology }\end{array}$ & Dhaka \\
\hline 10. & $\begin{array}{l}\text { Professor Sohrab Uddin Institute of } \\
\text { Medical Technology }\end{array}$ & Tangail & 28. & $\begin{array}{l}\text { Jaypurhat Institute of Medical } \\
\text { Technology }\end{array}$ & Jaypurhat \\
\hline 11. & $\begin{array}{l}\text { Prime Institute of Science and Medical } \\
\text { Technology }\end{array}$ & Rangpur & 29. & Institute of Medical Technology & Rajbari \\
\hline 12. & Trauma Institute of Medical Technology & Dhaka & 30. & CSSR Institute of Medical Technology & Chittagong \\
\hline 13. & $\begin{array}{l}\text { Bangladesh Institute of Medical } \\
\text { Technology }\end{array}$ & Pabna & 31. & Institute of Medical Technology & Faridpur \\
\hline 14. & TMSS Medical Technology Institute & Bogra & & & \\
\hline
\end{tabular}

Source: Complied data from PCB ${ }^{19}$ 
who pass this certificate course are categorized as ' $\mathrm{C}$ ' grade pharmacists by PCB and they usually work in community pharmacy or run their own pharmacies. However, since there is no compulsory requirement or obligation of having any form of qualification and knowledge to be 'Medicine-sellers in Pharmacies', this certificate programme is just available on paper without any hands-on training. Anyone hardly, takes this programme.

\section{GOVERNANCE OF PHARMACY EDUCATION}

The governance of Pharmacy Education is a complex task. Governance oftertiary level Pharmacy Education is slightly simpler than the diploma provision especially for private counterparts. First part of this write-up describes the regulation of tertiary level Pharmacy Education. The second part examines the complexity in offering diploma level Pharmacy Education.

\section{GOVERNANCE OF TERTIARY LEVEL PHARMACY EDUCATION}

Universities in Bangladesh are to be affiliated with the University Grants Commission -UGC (a commission created according to the Presidential OrderP.O. No 10 of 1973 of the Government of the Peoples' Republic of Bangladesh) in order to start their operation. Public universities enjoy more liberty in offering the programmes and revising the course curricula compared to their private counterparts due to the constitutional differences. However, in order to offer 'heavy weighted' professional programmes, a simple approval from the UGC is not sufficient. Universities also need to follow the governance and regulatory control prescribed and imposed by the respective controlling agency and professional body. Since pharmacy is a professional subject, the Government of the People's Republic of Bangladesh promulgated Pharmacy Ordinance (No. X111) in 1976 and set up Pharmacy Council of Bangladesh(PCB) under the Ministry of Health and Family Welfare. From then the pharmacy courses are designed and controlled by the PCB. To ensure quality teaching and to meet the high professional standard of the pharmacists, PCB initiated 'A grade' registration examination system for the pharmacy graduates of different universities in 2005. Pharmacists having ' $\mathrm{A}$ ' grade registration are eligible to practise pharmacy within the country.

\section{GOVERNANCE OF DIPLOMA LEVELPHARMACY EDUCATION}

Theoretically, by the virtue of the Technical Education Act-1967, diploma level education has to be offered by the polytechnics or polytechnic level institution with an affiliation and approval provided by the Bangladesh Technical Education Board (BTEB). No further 'Act or Ordinance' has been legislated in order to address this confusion. According to the BTEB, with the scope of current legislative framework, the name of diploma qualification cannot be used by any provider and regulatory body or professional agency without the approval of BTEB, albeit there is a confusion defining Pharmacy Education as technical or non-technical subject. Without having any collaboration with BTEB, PCB started providing diploma education. Challenging the PCB,the BTEB has also lately started working in the area of Pharmacy Education via its affiliated private institutes. "The quality of course curricula and capacity of these institutes are questionable". "It has created a significant amount of heated debates amongst different ministries, controlling and professional bodies. This is not only a threat to quality concern but also to the identity crisis of the graduates.

\section{PHARMACEUTICAL MANUFACTURING AND DRUG SELLER INDUSTRY}

The official development of pharmaceutical industries started slowly after the eleven years of independence in 1982 by promulgating "Drug Control Act". Until the year of 2000, Two hundred Ten licensed allopathic drug-manufacturing units were existed. Of 210 , only one hundred seventy three were active in production; the others were collapsed either due to the business challenges or non-compliance to good manufacturing practices or drug laws. As one of the fastest growing industries, the total size of the 'pharma-market' in Bangladesh was estimated to be BDT $28,416^{1}$ Million in 2004. With an annual growth rate of more than $10 \%$, the sector is now heading towards self-dependency in meeting the local demand. Reducing import, the sector has started exporting to few developing nations. Currently, imported drugs in Bangladesh mainly comprise of the cancer drugs, vaccines for viral diseases, hormones. Pharmaceutical industry hasnow become the second highest contributor to the national revenue earning after garments, and "it is the largest whitecollar intensive employment sector of the country".

1 One US \$ equivalent to Seventy Eight BDT (Bangladesh Taka) 
Although, foreign and franchise based industries are in operation, local companies are majority of market share reaching to $80 \%$. There are about 450 generics registered in Bangladesh. Of these, 117 are in the controlled category i.e. in the essential drug list and the rest are in the decontrolled category. The total number of brands/items that are registered in Bangladesh is currently estimated to be 5,300 , while the total number of dosage forms and strengths are 8,300.There were, however, 1,495 wholesale and about 37,700 retail drug license holders in 2000. This figure is increasing dramatically.

\section{INSTITUTIONS DELIVERING MEDICAL SERVICES}

The growth and development of public sector institutions delivering health care service maintain an increasing trendeven though political objectives sometime may hinder the balanced development throughout the country. ${ }^{3}$ Political objectives also develop a quantitative expansion sacrificing qualitative nature. Because of shortage of required number of professionals, weak management, lack of professional \& institutional competencies \& commitments and ethical downfall of the professionals; public institutions are not functioning well. Using these shortcomings, mushroom growing private sector mainly shares human resources employed in the public sector by part-time employment.This seriously affects the health care service of public sector. Private sector equally contributes for qualitative and quantitative growth. Recently, a good number of world class private hospitals have been set up in Dhaka. On the other hand, 'one room private clinics'are also readily available in the cities and in various places serving the needs of different cluster of people.

\section{ROLE OF PHARMACY EDUCATION ON DEVELOPMENT}

Both public and private sectors' involvement in pharmacy education play major role in development. Graduates from public sector hold the key responsibility in pharmaceutical manufacturing industry along with their international expertise colleagues. ${ }^{6}$ Even though there is a high demand of graduates from public sector in manufacturing industry, a high proportion of these graduates have to work for pharmaceutical research and administrative services forcing the industry to depend on the workers 'unofficially graduated' through 'work place learning'. Involvement of private sector in Pharmacy Education with questionable quality has now at least ensured a minimum level of supply chain of required graduates. Therefore witha proper legislative framework and its decent implementation, private sector would be a new horizon for Pharmacy Education.

\section{DEMAND VS SUPPLY AND IMPACT ON DEVELOPMENT}

There is an on-going interesting debate on demand and supply gap in area of professional education in developing nations. One group of the scholars argues that because of budgetary constraints, education system in developing countries fails to supply adequate amount of required professionals. The other group solicits that because of the economic crisis of the users residing in the nation, professional are less paid which forces them to migrate overseas for better future; therefore even there is a supply made by the education system but the gaps still exist. ${ }^{12,20}$ This poses a thought provoking moral question; is it ethical for the graduates who have spent public and private funds of their own nation to serve for other nations while their country of origin is in need of skilled professionals in their field of expertise.

While there is minimum level of supply chain of graduates required for manufacturing industry, the scenario in hospital and clinic is more disappointing because of the existing policy \& its poor practised and lack of supply of graduates. After the four decades of independence, the health care management in the government sector is still significantly poor. ${ }^{21}$ (World Health Organization, 1992). Only the physicians and nurses are working in the hospitals as caregivers. A health care provider team in the countries those enjoyed well reputation consists of a physician, a pharmacist and a nurse. Evidence confirms that 'no graduate' pharmacists are serving in the government hospitals in Bangladesh as health care providers for proper drugs and diseases management. ${ }^{7}$

A diploma graduate pharmacist leads the pharmacy department available for the patients in the public hospital.This pharmacist just dispenses and distributes the medicines. Due to the poor and incomplete health management system in Bangladesh, prescription errors are very common and many patients suffer from severe complications and even die. There is no clinical pharmacist in any public hospital in Bangladesh who can study to rationalize the individual dosage regimen for the patients suffering from either liver or kidney diseases. Developed country employ $40-50$ pharmacists work in out-patient, inpatient and emergency/ambulatory, and in clinical departments in a tertiary level hospital.

Some private hospitals in Bangladesh have lately employed several graduate pharmacists in their outpatients pharmacy departments. But no pharmacists are working in the in-patient department for proper monitoring and management of drugs. At present, about 30-40 pharmacists are working in private hospitals and 
in some 'high class' retail pharmacy located in Dhaka. However, most of the private hospitals have been operating without employing a pharmacist. ${ }^{7}$

The problem of ignoring employment of pharmacists in pharmaceutical retail outlets is manifold. With absence of regulation and its implementation'no Medicine-sellers in Pharmacies of urban Bangladesh" has obtained any form of qualification in pharmacy. ${ }^{8}$ If this scenario exists in anurban area located in Dhaka, assuming the scenario of rural area is not a very complex task. This situation results more costs to be paid for public health care in the long run. While economic drawback of this situation may be quantified, its impact on social development isun-quantified.

\section{STRATEGIC PLANNING AND POLICY}

In order to chalk out the strategic plan and future policies, the following key findings are hereby discussed: Surprisingly, employing the full-time academics from public institutions on part-time basis, private sectorsare challenging the counterparts from multiple positive and negative angles. While both the public and private sectors have a scope to arrange collaboration with the industries in order to produce high quality graduates, both sectorsignore. Ignoring this reality, public sector with their longstanding laboratories are trying to produce backdated graduates at highcosts, private sector produces graduates in black and white with a lower unit cost. Hence, a decent operational "Memorandum of Understanding' between industry and institution of education would play a constructive role. Private sector works in a competitive atmosphere.

To survive in a competitive market, private education is always aware of job market patterns. A global phenomenon testifies that while public educations ignore job market patterns, the private institutions attempt to fill the gaps. Both the manufacturing and retailing pharmacy industries and the private sector education are belonging to private entrepreneurs. Hence, there is a very good scope for both to work collectively in providing high quality pharmacy education.

Capable students in public sector are forced to study their unlisted subjects because of rigid selection process and limited seats. On the other hand, not-so-intelligent students in private sector are pursuing higher degrees in pharmacy which are beyond their intellectual capacity. Bright students having financial ability are now in private education because they have been rejected by the public counterparts to study desirable subjects. Initiating a voucher system, government can make collaboration between public and private sectors so that the capable students from the poorer background can either use the public or private sector by the usage of voucher providing a bond either to work for the nation or to repay the amount after the employment. On the other hand, students from privileged background should pay their user fees either for using public or private sector with a liberty of any form of employment in the country after the graduation.

Because of the 'market driven'demand created by the 'existing state public policy', both the public and private sectors target the same group by delivering similar types of programmes and degrees. Moreover, there is no legal obligation for the employees to have a proper qualification in pharmacy in order to work for hospital, clinics and retail sectors. Government should determine a minimum qualification in Pharmacy required for a particular role. Both the employees and employers are to be obliged to confirm that employees must be having the predetermined qualification either via preservice or post-serviceeducation. Identifying the institutional strengths and weaknesses of both counterparts and justifying the competence of the students studying in public and private sectors, the role and boundary of public and private education are needed to be redefined and confined. Consequently, this will help to educate the currently unattended group.

Currently, in absence of community pharmacists, most of the drug manufacturing companies are employing young graduates to sell and to advocate their products to the doctors and users. This particular job portfolio is called as "Medicine Representative'. These representatives do not have any prerequisite pharmaceutical knowledge prior to join with the job. The main competencies are considered 'their physical look' and their'marketing skills'. Since 'look' is considered as a main parameter, the longevity of this careerstands until they look attractive. Consequently,after a certain point, either they are forced to leave the sector. Moreover, look parameter brings a discrimination within the employment pattern. These 'representatives' accrue necessary pharmaceutical and marketing skills as part of their in-service career. Since no institutional bodies are examining their level of competencies, they lack 'paper qualification'. Taking this scope, a determined salary structure is ignored. It is now therefore urgently important to provide the recognition and validation of their knowledge by introducing a 'grade based test'. This will help to ensure astructured salary package to address the discrimination.

With the current settings of governance and regulatory control for Pharmacy Education, good quality education can possibly be provided. In contrast, achieving international standard and globally validated recognised qualification framework for Pharmacy Education is 
merely impossible. It is thus without any further delay, this problem needs to be addressed.

\section{CONCLUSION}

With the scope of the paper and available data, conducting a comprehensive comparative study using a number of countries within Indian Sub-continent was not possible. However, we may note that countries in Indian Sub-continent share same pattern especially for education and social issues since their colonial heritage. India is the broader territory which guides most of the countries located within the Southern Asia. The images presented in this paper essentially represent Bangladesh; however, most of the countries within Indian-Sub continent will be benefited through the findings and discussion of this paper as all most all of countries share similar experiences.

It is thus, the concluding remark suggests that the legislators should re-examine the roles and responsibilities of both sectors reflecting on the possible ways to dissolve the differences which can complement each other. This may contribute to greater access, equity, quality and competitiveness of Pharmacy Education in supporting the national development and international competitiveness of Pharmacy Education.

\section{ACKNOWLEDGEMENT}

The authors would like to express their sincere appreciation to the Editor-in-Chief and the two anonymous referees for their valuable suggestions which helped improve the quality of the paper immensely.

\section{CONFLICT OF INTEREST}

This research study has no conflict of interests.

\section{REFERENCES}

1. Ahmed Syed Imran, Mohamed Azmi Ahmad Hassali. The controversy of Pharm. D. degree. American journal of pharmaceutical education. 2008; 72(3): 3-71.

2. Babar Z. Pharmacy education and practice in Pakistan. American Journal of Pharmaceutical Education. 2005 5(69): 1-3.
3. Chowdhury AKA. Pharmacy education in Bangladesh: past, present and future. BAPA Journal; 2007. 10-14.

4. Ghilzai, Naushad Khan M, Arjun Dutta P. India to introduce five-year doctor of pharmacy program. American Jjournal of pharmaceutical education. 2007; 71(2): 2.

5. Jamshed, Shazia, ZaheerUd Din Babar, Imran Masood. The Pharm D degree in developing countries. American journal of pharmaceutical education. 2007; $6(71): 125$

6. Alam, Gazi Mahabubul. Impact of private higher education on Bangladeshi education system: an investigation of education policy. VDM Publishing; 2008.

7. Mazid MA, Rashid MA. Pharmacy Education and Career Opportunities for Pharmacists in Bangladesh. Bangladesh Pharmaceutical Journal. 2011; 1(14): 1-9.

8. Rahman, Saifur, Mohsin U, Ahmed S. Can medicine-sellers in pharmacies meet the needs of STD clients. Observations from an urban area of Bangladesh. Dhaka: ICDDR, B: Centre for Health and Population Research; 1999.

9. Alam MG. Can governance and regulatory control ensure private higher education as business or public goods in Bangladesh? African Journal of Business Management. 2009; 3(12): 890-906.

10. Alam, Gazi Mahabubul, Taher Billal, Khalifa Md. The impact of introducing a business marketing approach to education: A study on private HE in Bangladesh. Afr. J. Bus. Manage. 2009; 3(9): 463-74.

11. Alam, Gazi Mahabubul, Kazi Enamul Hoque, Taher Billal, Khalifa Md, Saedah Binti Siraj, Ghani MFBA. The role of agriculture education and training on agriculture economics and national development of Bangladesh. Afr. J. Agric. Res. 2009; 4(12): 1334-50.

12. Alam, Gazi Mahabubul, Kazi Enamul Hoque, Gyanendra Kumar Rout, Nibedita Priyadarshani. Who gains from EFA-State Business of Education or Private Higher Education Business in Developing Nation: A study to understand the policy impact in Bangladesh? Afr. J. Bus. Manage. 2010; 4(5): 770-89.

13. Alam, Gazi Mahabubul, Taher Billal, Khalifa Md, Mirja Mohammad Shahjamal. Return from education system in Bangladesh: an investigation on comparative flashback scenario. Afr. J. Bus. Manage. 2009; 3(10): 567-75.

14. Alam GM, Hoque KE. Who gains from Brain and Body Drain BusinesDeveloping/developed world or individuals: A comparative study between skilled and semi/unskilled emigrants. African Journal of Business Management. 2010; 4(4): 534-48.

15. Thomas A, Potter D. Development, capitalism and the nation state. In T. Allen \& A. Thomas (Eds.), Poverty and Development in the 1990s. Oxford: Oxford University Press; 1992.

16. Alam, Gazi Mahabubul. The role of science and technology education at network age population for sustainable development of Bangladesh through human resource advancement. Sci. Res. Essays. 2009; 4(11): 1260-70.

17. UNDP Human Development Report. New York: UNDP; 2002.

18. Annual Report (87th), University of Dhaka, Bangladesh; 2007-2008.

19. UGC. Annual Report, University Grants Commission of Bangladesh, Dhaka, Bangladesh; 2010.

20. World Bank. Bangladesh: Promoting Higher Growth and Human Development. A World Bank Country Study. Washington, DC; 1987.

21. World Health Organization. Management of patients with sexually transmitted diseases. Geneva: World Health Organization. Technical report series. 1992; 810: $1-4$. 